\title{
Negation in Languages: A Urhobo Perspective
}

\author{
Iwuala, Zebulon Chukwudi \\ Department of Linguistics and Nigerian Languages, National Institute for Nigerian Languages, Aba, Abia State, Nigeria \\ Imu, Famous Oghoghophia \\ Department of Linguistics and Nigerian Languages, National Institute for Nigerian Languages, Aba, Abia State, Nigeria
}

\begin{abstract}
This paper examines negation and types of tense negation in Urhobo. It also identifies negation marker(s) and the manner in which these negation marker(s) are used in sentences. Transformational generative grammar theory of analysis was used in the work. The aim of this study is to determine the syntactic characteristics of negation in Urhobo. The study shows that negative construction in the Urhobo language involves the doubling of the last vowel of the last word in sentences; or what may be called the lengthening of the last vowel of the lexical item in the sentence. Also, the low-high tone can do the same function as the lexical or grammatical tone. It was observed that negation is a natural phenomenon that cuts across Urhobo, and that the orthographic representation of the low tone, which is the copying of the final vowel, is written contiguously while other negative markers are written separately. It was also observed that Urhobo operates suffixation. Finally, the study work reveals ejo, je, odie and and oyen as negative markers in Urhobo.
\end{abstract}

Index Terms-Negation, negative marker, syntactic characteristics, tense, Urhobo

\section{BACKGROUND TO THE STUDY}

Negation is language universal and exists in one form or the other in natural languages, because at one point or the other, the need to negate, refute, deny, contradict or lie arises. It is used to distinguish positive statement and its negative counterparts. The importance of negation as it affects all natural languages cannot be under estimated, and so Urhobo is not an exception.

Negation has been studied in English, Igbo, Yoruba, and Isekirin in such works as Ahamefula (2010), Anagbogu (2005) Manda, (2012), Ndimele, (2005,) Nwaozuzu, (2008), Nwarungwa, (2013), Odii, (2016). Teke, (2004) and Zeijista, (2004)). Some of these studies range from lexical negation to sentence negation. Research has shown that more studies have been done on grammatical negation by the above scholars. Negation as an aspect of Urhobo syntax is yet to receive proper attention. Taiwo (2009) in class discussion confirmed this in the following observation; "Urhobo is one of the minority languages in Nigeria that its syntax is yet to be explored". Although earlier works have been done on negation in the Urhobo language, much has not been done on negation as it operates in Urhobo. Negation has been studied from two types: lexical negation and grammatical negation.

Lexical negation is the type of negation that negates one or more constituents in a construction e.g

1. Wo je hwa osa na je wo fi igho

You NEG pay that NEG you spray money

You have not paid your debt and you are spraying money.

While grammatical negation is that type of negation that negates a whole sentence. e.g

2. Ititi vwe ogoo

Name get respect NEG

Ititi is not respectful.

In Urhobo, negation could be found in statements, commands and questions (see Aziza 2004).

There are two basic tones in Urhobo, namely, the low (L) tone and the high $(\mathrm{H})$ tone. It should be noted that only vowels bear tones in Urhobo. The tone marking system used in this study is as popularised by Aziza (2006) with the claim that Urhobo Language operates two basic tones; the high and the low tone. This tone marking system has been used in Aziza (2006). This tone marking system is preferred because of its economy of diacritics. The two basic tones are marked as follows: The high tone is marked by " $\mathrm{H}$ " while the low tone is marked by " $\mathrm{L}$ "

The aim of this study is to look at the phenomenon of negation with emphasis on Urhobo. Thus, this research tries to examine:

i. the syntactic characteristics of negation in Urhobo with a view to ascertaining whether there are peculiar tonal properties associated with the phenomenon of negation.

ii. whether the phenomenon of negation cuts across Urhobo.

iii. the lengthening of negative particles in sentence construction

iv. the functions of the low-high tone and

v. the negative markers in Urhobo 


\section{LITERATURE REVIEW}

\section{A. Theoretical Studies}

Phrase structure rules of the generative grammar are an amalgam of the subject-predicate and parsing systems of the traditional grammars and the immediate constituent analysis of the structural grammar. They are framed to derive a 'kernel' sentence (Chomsky 1957), or 'underlying (deep) strings (Chomsky 1965). These rules define basic grammatical relations that function in the deep structure. Phrase structure grammar was founded by Noam Chomsky in his book Syntactic Structures in (1957). PSG is a re-write grammar with finite rules that generate infinite sentences in human language ((Mbah 1999 and 2006), Anagbogu, Mbah and Eme (2010) and Asogwa, Nwaozuzu and Mbah (2013). The phrase structure of a sentence is generally represented by a tree diagram. The points that are joined by the lines or branches are called 'nodes'. Each of the nodes, except those on the bottom line (which are the terminal nodes) is given a label that represents grammatically definable constituent - N, V, NP, VP, etc. where one mode is higher than another and joined to it by branches. PS grammar does not have the precision, simplicity, elegance, power, insight, and competence of the TG grammar. PS grammar is very complex, cumbersome and clumsy with so many constraints. PS grammar fails to account for negation process.

Consequently, because of the above shortcoming of PSG, Chomsky came up with a revision which he called Transformational Grammar in (1957). Transformational generative grammar refers to the grammar based on the observation of languages and theories about the general principles involved in producing language. The theories are subjected to a series of tests based on observed phenomena about language. Transformational Grammar (TG) is the foundation upon which other generative theories and approaches are built. Transformational grammar accounts for clarity of meaning (Kelly 2013).

Mbah (1999 and 2006), asserts that 'transformation' or 'change' is an aspect of the syntactic component of language. Thus, it is always the inadequacies of one theory that gives birth to a fresh or new theory. In other words, the grammar of a language could merely consist of a catalogue of the number of its grammatical sentences.

Chomsky (1957, 1964 and 1965) disagrees with a grammar listing sentences in a language as weak and nonviable. He maintains that a grammar must be projective and generative. Projective grammar contains rules which generate the number of infinite possible grammatical sentences in a language whereas generative grammar has rules capable of generating sequence of lexical items that are grammatically accepted by the speaker-hearer of the language even when they have not come across such grammatical statement(s). As part of his linguistic revolution, Chomsky (1957) modifies the Standard Theory and named it the Extended Standard Theory (EST): The theory tries to solve the challenges or the differences between the deep and the surface structures of sentences. It distinguishes between syntax and semantics and makes each autonomous. The autonomy of syntax in Extended Standard Theory (EST) means that we can explain the structure of a language without any reference to semantics.

However, it should be noted that several versions of syntactic theories have sprung up since it was first presented by Chomsky in 1957. Right from 1965, it has witness four major revisions. The 1965 version which was represented in Chomsky's monumental book Aspects of the Theory of Syntax was referred to as Standard Theory (ST).

By the beginning of the 1970s, there was need to modify (ST) by the fact that surface structure also contributes to meaning, hence the version transformational generative (TGG). At a point in time, it was called the Extended Standard Theory (EST). In the late 1970s, there was also the need to modify the version, so as to account for traces at the argument level; the dominant model of syntactic analysis during the period was referred to as the Revised Extended Standard Theory (REST).

In the early 1980s, Chomsky felt the need to revise the theory again, hence the model was known as Government and Binding Theory (GB). The more advanced generative grammar has become the more it has tried to raise its goals. TGG accounts for negation classification, description and movement transformation as affix hopping. (see Anagbogu, Mbah and Eme (2010), Kelly (2013) and Zeijlstra (2004).

With advances in analytical techniques and the range of languages examined, generativists felt that they were gradually in a position to make claims about grammar as it applies to all languages. This is the technical meaning of the term universal grammar. Mbah (2011) sees universal grammar as the body of structure which is common to all languages and specific to none. Universal grammar is furthermore concerned not just with saying that languages have certain structural features but with accounting for why this is the case. The details of universal grammar are quite complicated as they involve a highly formal analysis of possible syntactic structures and terminology with which the reader is not initially acquainted. Any model of universal grammar, if it is to achieve the higher goal of explanatory adequacy, must have three attributes: 1) Universally valid, 2) Psychologically real 3) Maximally constrained.

The first feature is obvious and refers to the fact that universal grammar applies to all human languages, both presentday languages and those which are extinct as well as possible future languages. It maintains that the universal grammar must be in keeping with what one knows about the psychology of language (see Ndimele, 1992). The last attribute explain that the model must ban rules which are universally impossible (Crystal, 2008).

\section{B. Theoretical Frame Work}

This study is carried out using the frame work of transformational generative grammar. Its aims is not only to classify and describe utterances but to also capture regularities that underlay them, thereby making predictions of what may be 
expected and what may not be expected. Transformational generative grammar was propounded by Naom Chomsky; the theory has undergone series of changes since its inception in 1957. This syntactic theory, made popular in Syntactic Structures (Chomsky, 1957) is widely seen as the heart of modern theoretical linguistics (Newmeyer, 1980).

However, since the introduction of Standard Theory, a model published in the Aspects of the Theory of Syntax (Chomsky, 1965). In a nutshell, since the early 1970, Standard Theory has undergone four major modifications: The Extended Standard Theory (EST), the Revised Extended Standard Theory (REST), the Government and Binding Theory (GB) and currently the Minimalist Program (MP).

The essence of the different versions of the theory is to find a simple tool for describing adequately man's natural languages. Each of the above mentioned versions of the theory is a model in the quest for an appropriate linguistic theory in the transformational generative theoretical frame work. This frame work is relevant to this study because TGG accounts for what the native speaker has in mind, which conveyed to the surfaces structure. TGG accounts for the description of negation process of the Urhobo language, Universal grammar is relevant to this study, using a descriptive approach.

\section{Empirical Study}

Donwa (1982), and Omamor, (n.d.) investigate negation in Southwestern Edoid languages such as Isoko, Urhobo and Okpe, languages considered as having single form of negation. The aim of the research was to investigate whether it was possible to work out a single method of negation in Southwestern Edoid languages. Their findings show that it is possible to work out a single analysis for negation in SWE.

Aziza and Mowain (2006) investigate yes/no questions and sentence negation. A descriptive method of analysis was used. Their aim was to find how tone interacts with syntax in the derivation of yes/no questions and sentence negation, their findings show that yes/no questions and sentence negation exhibit peculiar tonal characteristics, it also provides evidence of phonology-syntax interface in the classification of certain sentence types. This work differs because we are looking at tense negations and negative markers in Urhobo using TGG as a theoretical framework.

Aziza (2005) and Ukere (2004) in a class discussion faulted the use of hyphen and countered the position of the hyphen saying it cannot be accounted for syntactically. The Urhobo Study Association, Delta State University saw reasons in their argument, and adopted the orthographic representation of the low-high tone negative marker, and that it should be written contiguously without the hyphen.

Aziza (2010) studies negation in Urhobo, She carries out a descriptive study of negation in Urhobo. She identifies the types of negation to include; negation in statement, command and negation in question. The aim of the study was to determine the status of some suprasegmental features noticeable in negative constructions in Urhobo, and to highlight a common ground for a single description of the phenomenon of negation in southwestern Edoid. Again this research differs from the formal because we will examine tense negation and, identify grammatical negators in the Agbarho, dialect of Urhobo, using TGG as a theoretical framework.

\section{Summary of Literature Review}

This section of the paper reviews scholarly works in the area of study. Objectively the review shows that much has been done on negation in other languages, works on negation as they operates in Urhobo are either negligible or nonexistence, hence the need for this research. Therefore, this research is relevant because, it will add to the existing literature on the grammar of the Urhobo language.

\section{NEGATION IN URHOBO}

Negation is a universal phenomenon applicable to all human languages. Negation can be seen as the grammatical process by which the truth of clause or sentence is defined, involving the use of negative words. Negation implies the assertion that certain proposition is false, the act of contradicting a statement or allegation. In this paper, we shall examine tense negation, negation in interrogative constructions, identify negation markers and describes how the phenomenon operates in Urhobo.

\section{A. Tense Negation}

Tense is the relationship between the form of the verb, the time of the action and the state the verb describes, while Odii (2016), defines tense as the relationship between the verb, the time it expresses, the condition it describes and the negator that contradicts the time and the action expressed by the verb. Therefore, tense is the agreement or the relationship between the subject(s) and object of a sentence. Aziza (2005) identifies the present tense, past tense and the future tense in Urhobo, these types of tense shall be considered in conjunction with negative construction in the Urhobo language.

\section{Present tense negation}

The present tense construction in Urhobo is used to convey habitual as well as present or continuous situation/action. The morpheme marking the tense is a floating high tone which occurs at the subject noun phrase. The data below illustrate present tense and their negated counterpart in Urhobo. e.g 
H L H L L L

3) a Ese e de obe

Ese pres buy book

Ese buys/is buying a book

LH L HL

b. Mi i kpe eki

I pres go market

I am going to the market

L L H LH

c O me e eto

She plait pres hair

She is plaiting hair

L L L H L L L

d. Okoro o se ebe

Name read book

Okoro reads/is reading a book
4) a. HLH L L L H

Ese e de obee

Ese pres buy book NEG

Ese is not buying a book.

b. $\quad \mathrm{LH} \mathrm{LHLH}$

Mii kpo ekii

I pres go marketNEG

I am not going to the market

L L H LLH

c. Omee etoo

She plait hair NEG

She is not plaiting

L L L H L LLH

d. Okoro o se ebee

name press read book NEG

Okoro is not reading a book

In present tense negative, there is the presence of a high floating tone in the positive form. This floating high tone is mapped on the final vowel of the affirmative form causing it to be lengthened in order to accommodate the tone sequence via transformation process (affix hopping), this is the case as seen in example (4a-d), while example (3a-d) are the positive forms with the presence of high tone indicating the construction to be in the present tense.

\section{Past tense negation}

The past tense construction in Urhobo is used to convey past tense situation/action. Tonally, the past tense construction assigns a tomorph which is segmentalized on the vowel segment of a monosyllabic verb stem or on the final vowel of a disyllable verb stem. This is clearly shown in the example below.

H L L $\mathrm{H}$

5).a Ese de re

Ese buy pst

Esebought it

L L L H L L

b. Onime kpe eki

Mother my go market

My mother went to market

L L L H L H

c. Okoro kwe omo na

Name kill child that

Okoro killed /beat the child
H L L LH

6).a Ese de ree

Ese de re NEG

Ese did not buy it

L L L L L LH

b. Onime kpe ekii

Mother my go market NEG

My mother did not go to market

L L L L L L LH

c. okoro kwe omo naa

Name kill child that NEG

Okoro killed /beat the child

Urhobohas modal morphemes used to express moods, they are verbal, and part of the auxiliary verb. e.g fobo (be early, quick), ghwa (just, already) pha (condition) ma(deliberate)

L L L LH

e. Wo fobo rhee

You quick come NEG

You did not arrived early

In the past tense negative construction, the presence of the high tone does not spread onto other vowel segments within the verb stem like the present tense construction does. In example $(5 a-c)$ the presence of the floating tone is noticeable, while in example (6a-c) the high floating tone get segmentalised on the final vowel in the suffix position, causing it to accommodate the tone sequence.

\section{Future tense negation}

The future tense is marked by a particle, which occurs between the subject noun phrase and the verb stem of the sentence. This particle is realized in two forms /che/ and /cha/ depending on the vowel harmony rule based on the verb stem vowel. If the verb stem vowel is (+ART), it selects (che) and if is (-ART), it selects (cha). This future tense is used to indicate an action that is yet to commence or one that is being contemplated (Aziza 2005). This is clearly illustrated in the data below.

$$
\text { L H H }
$$

7).a O cha de

He/She particle buy

He/She will buy it

L $\mathrm{H} \quad \mathrm{H} \mathrm{L}$ L H

b. O cha kwe evwe na

He/She particle kill/beat goat that

$\mathrm{He} / \mathrm{She}$ will kill/beat the goat
L $\mathrm{H} \mathrm{HH}$

8).a O cha dee

He/She particle buy NEG

$\mathrm{He} / \mathrm{She}$ will not buy it

L $\quad \mathrm{H} \quad \mathrm{H}$ L $\mathrm{L}$ HH

b. O cha kwe evwe naa

He/She particle kill/beat goat that NEG

$\mathrm{He} / \mathrm{She}$ will not kill/beat the goat 


\section{L LH}

c. $\mathrm{O}$ che ruo

$\mathrm{He} / \mathrm{She}$ particle work

He will do it

L L LHLL H

d. O che chere emu na

$\mathrm{He} /$ she particle cook food that

She will cook the food
L L LHH

c. $\mathrm{O}$ che ruoo

He/She particle work NEG

He will not do it

L L LHLL HH

d. O che chere emu naa

$\mathrm{He} / \mathrm{she}$ particle cook food that NEG

She will not cook the food

Example (7a-d, and 8a-d), shows that the negative particles that mark the future tense negation are realized, depending on the vowel harmony selected. The future tense negation markers show that tonal alternation in example (8a-d) result from the segmentalsation of the two tones marking the future tense.

\section{Perfect tense negation}

The perfect tense construction in Urhobo is used to indicate an action or state that has been completed at the present time in the past, or will be completed in the future. The morpheme marking the tense is a floating high tone which occurs at the subject noun phrase. The data below illustrate perfect tense negation in Urhobo. e.g

\section{H L L LH}

9)a. $\quad$ Mi se obe nure

I read book finished

I have finished reading the book

L HLL L HLL

b. Mi re emu okieeje

I eat food time all

I eat food all the time
L L L L H LH

10).a Mi je se obe nuu

I have read book finish NEG

I have not finished reading the book

b. L H H L L HLLH

Mi re emu okiejee

I eat food every time NEG

I do not eat food all the time

Negation in Urhobo is marked by the presence of a floating LH tonal morpheme which is realized on the final vowel of the affirmative form causing it to be lengthened in order to accommodate the tone sequence (Example 9a-b), while negative adverbs always occur clause finally and bear the tomorph (example 10a-b), negation particles follow immediately after the subject of the clause and, just like pronouns, always occur in two phonological forms depending on the vowel harmony associated with the verb stem vowel. eg ocha dee (he will not buy, oche ruoo (he will not do it), (see example 9 and 10 ).

\section{B. Imperative Negation}

An imperative sentence is used to express a command, or make a request. The command may be positive or negative. In positive commands, there is no overt subject at the surface form and nouns and verbs retain their tones as in the citation form but with a lot of force in the voice, the final low tones are not raised and final high tones do not fall. This is a type of negation where part of a sentence is negated such as the noun phrase.

\section{H L H LL}

11a. Wo vren ne etine

You(sg) leave here

You leave here!

\section{L H L LH}

b. Wan hworhe iko

You wash (pl) cup

You wash cups!

L L H LLH L H H L H

c. Wo hwe fikiridie okpako Ekru

You kill because elder family

Kill him because he is an elder in the family!
L H L H LLH

12a. Wo vren ne etinee

You(sg) leave here NEG

You don't leave here!

L L HLLH

b. Wan hworhe ikoo

You (pl) wash cups NEG

You don't wash cups!

L LH LLH L H H L H L

c. Wo hwee fikiridie okpako Ekru you kill NEG because elder family

Do not kill him because he is an elder in the family.

Example (11a-c) is the positive form of imperative negation. The negative counterpart is realised by the introduction of a negative particle which entails the lengthening of the vowel on the suffix. This is the case in example (12a-c).With the introduction of a high floating tone on the suffix, the entire sentence becomes negative. It should be noted that imperative sentences are derived from declarative sentence through transformational process.

\section{Negation in Interrogative Constructions}

Questions, whether negative or positive, are marked by an L question tomorph which gets segmentalised on the final vowel. This question tomorph does not displace the lexical tone borne by the final vowel but contracts with it, if they are identical, or forms a HL contour if they are not. Thus, all questions end on a low tone. In questions construction, the last but one $\mathrm{H}$ tone of the construction is realized on an extra high pitch $(\mathrm{H})$ and its effect is that final Ls begin to fall from this height thereby preventing a final downglide where the statement already formed ends on a L tone. In negative questions, another floating $\mathrm{L}$ which marks NEG also gets segmentalised finally and results in final vowel lengthening, although the length of the final vowel is shorter in negative questions. The presence of two $L$ tomorphs, i.e. the question and negative tomorphs side by side results in a final downglide (Aziza and Mowarin 2006). E.g 
(13) $\mathrm{a}$
HL H H H HL
a. Ese de oka naa?
Name buy maize NQ
Didn't Ese buy maize?
b. L L H HLL
Wo de udii?
You drink wine
Are you drunk?
L H H H L L H(L)
c. tivo mi da re onee?
Where I Aux eat yam Q
Where did I eat yam?

\author{
HL H HHHLL \\ 14)a ejo Ese de oka naaa \\ No name buy maize that NQ \\ No, Ese didn,t buy maize. \\ L L L L H HLL \\ b Ejo mi de udiii \\ No I drink wine NQ \\ No, I am not drunk \\ LL LHLLL LL HH LLHLL \\ c. Odie enu imedge oyen mi da re oneee \\ NEG top table I Aux eat yam NQ \\ I didn't eat yam on the table
}

From example (13a-c and 14a-c), we notice that negation in question is marked by a floating L-H tone sequence, which is mapped unto the final vowel in the phonetic realisation. However, negativisation occurs when a negative marker is introduced into the asserted sentence (Aziza 2005). One of the major negative markers in example (14a-b) is 'ejo' which means "no". Ejo is used to give a negative respond or statement. It is a lexical item for negation that has an affirmative counterpart "E" which implies "yes". "E" according to Urhobo-English dictionary by Ukere is used to give response to most greetings and directive. Ejo is used to express the rejection of a suggested preposition i.e it is a rejective type of negation. While 'Odie' and 'oyen' negative markers are often used for negating whole sentences in constructions where 'odie' appears in the initial position 'oyen' appears at medial position (see example 14c).

From the evidence presented in the foregoing sections, it could be concluded that negation in Urhobo is manifested mainly through tones with intonation superimposed on the surface realizations of these tones in various construction types. Although negative adverbs and particle also exist, they are used mainly for emphasis and for extra information and occur conjointly with tones.

\section{SUMMARY OF FINDINGS}

The research reveals that negative markers in Urhobo are associated with a low- high tone on the final vowel; in the present, past, future and perfect tense constructions and in the suffix position. This is shown in example 3-12 above; with the use of the L-H tone all sentences can be negated.

This paper also reveals that negation is a natural phenomenon that cuts across Urhobo which is the copying of the final vowel, which is written contiguously, while other negative markers are written separately. This is the case of example 3-12 and 13 above.

It also, reveals that the low-high tone can function as lexical or grammar tone in negative constructions. This means that the L-H tone could bring about change in meaning of words. (See example 3-12 above.) In addition, there is doubling of the last vowel of the last word, what we could call vowel lengthening. The low-high tone can do the same function as the lexical or grammatical tone. This means that lengthening of the negative particle can make a construction either positive or negative. (see example 3-12.)

The study also identifies je, ejo, odie and oyen as negative markers in the Urhobo language. Ejo, odie and oyen negative markers are often used for negating a whole sentence. The study reveals that these types of negative markers occur at sentence initial and medial positions. Finally, where odie appears in the initial position oyen appears in medial position (see example 13a-c) .

\section{CONCLUSION}

This research has shown that negative sentences are derived by the introducing negative marker(s) which occurs with tone and the lengthening of the last vowel of the last word(s). In natural languages, negation may be achieved using various strategies and a particular language may utilise more than one way in sentence construction. Common ways by which negation is achieved include phonological conditioning, morphological forms, negative auxiliaries, verbs or adverbials constructions.

\section{REFERENCES}

[1] Ahamefuna, N.O. (2010). Negator in Igbo syntax. M.A seminar paper, Department of linguistics, Igbo and other Nigerian languages, University of Nigeria Nsukka.

[2] Anagbogu, P. N. (2005). The negativizing prefixes of Koring. In O. M. Ndimele (Ed). Treds in the study of languages and linguistics in Nigeria: A festschrift for Philip Akujuoobi Nwachukwu (pp. 574-582). Port Harcourt: Grannd Orbit communications and Emhai press.

[3] Anagbou, P.N., Mbah, B.M. \& Eme, C. A. (2010). Introduction to linguistics (2 $2^{\text {nd }}$ ed.). Anambra: Amaka Dreams Ltd.

[4] Asogwa, P.N., Nwaozuzu, G.I. \& Mbah, B.M. (2013). Syntactic constraints in Igbo. Nsukka Working Paper in Language, Linguistics, and Literature (NWPLLL), 1(1\&2) 108-144.

[5] Aziza, R.O. (2004). Negation in Southwestern Ediod: The case of Urhobo. Proceeding, $4^{\text {th }}$ world congress of African Linguistics, New Brunswick, in A. Akinlabi and O. Adeola (Eds.), pp. 165-174, kolin: Rudiger Koppe. 
[6] Aziza, R.O. (2005). Phonological process in Urhobo. Lecture Note Abraka, Delta State University.

[7] Aziza, R.O. \& Mowarin, M. (2006). Phonology-syntax interface in derivation of yes/no question and sentential negation in Urhobo. JOLAN: Journal of the Linguistics Association of Nigeria No. 9 2005/2006.

[8] Chomsky, N. (1957). Syntactic structures: The Haggue Mouton. Massachussels, MIT press.

[9] Chomsky, N. (1964). Formal discussion on. The development of grammar in child language by W. Miller \& S. Ervin, in B. Belligi \& R. Brown (Eds). The Acquisition of language. (Monographs of sociology for research in child development 92) Child Development Publication

[10] Chomsky, N. (1965). Aspect of the theory of syntax. Massachussels, MIT Press.

[11] Crystal, D. (2008). A dictionary of linguistics and phonetics. Oxford: Blackwell.

[12] Donwa, E. (1982). The sounds system of Isoko. Ph.D thesis, University of Ibadan.

[13] Kelly, N. (2013).Transformational generative grammar and biblical studies. www.tgg research-paper-final-for-blog.pdf. retrieved on 15/01/17.

[14] Manda, I. M. (2012). Negativisation in Bassa language. UJAH: Unizik Journal of Arts and Humanities, 3 (1) 92-105.

[15] Mbah, B.M. (1999). Studies in syntax: Igbo phrase structure. Nsukka Prise Publishers

[16] Mbah, B.M. (2006). G.B. syntax: Theory and application to Igbo. Enugu. Enugu: St. Jon-Afam Publications

[17] Newmeyer, F. J. (1980). Linguistic theory in America. London and New York: A.P.I

[18] .Ndimele, O. M. (1992). The parameters of universal grammar. A G. B. Approach. Owerri: African Education Services

[19] Ndimele, O.M. (2005). Negation marking in Igbo, in O.M. Ndimele (Ed.), Trens in the study of languages and linguistics in Nigeria: A festschrift for Philip Akujuoobi Nwachukwu (pp. 939-956). Port Harcourt: Grand Orbit Communication and Emhai Press.

[20] Nwarungwa, J. O. (2013). Negation iO\#n Nwa dailect. M.A seminar paper, Department of Linguistics, Igbo and other Nigerian Languages, Nsukka. University of Nigeria Nsukka.

[21] Nwaozuzu, G.I. (2008). Dialects of the Igbo Language. Nsukka: University of Nigeria, Nsukka Press Ltd.

[22] Odii, B.C. (2016). Negation in the Okposi Lect of Igbo. Ph.D seminar paper, Department of linguistics, Igbo and Nigerian languages, Nsukka. University of Nigeria Nsukka.

[23] Omamor, A.P. (n.d). Introduction to the phonology of Okpe. Ms, University of Ibadan, Ibadan.

[24] Taiwo, B.O. (2009). Advanced syntax. A class discussion. Ibadan, University of Ibadan.

[25] Teke, G.T (2004). Negative polarity in Metta (Uta). In O. Ndimele (Ed.) Language and culture in Nigeria: A festschrift for Okon Essien (pp, 823-830). Port Harcourt: Emahi Printing and Publishing Co

[26] Ukere, A. O. (2004). Syntax of Urhobo. A class discussion. Abraka, Delta State University.

[27] Zeijistra, H.H. (2004). Sentential negation and negative concord. Amsterdam: JK Utrecht.

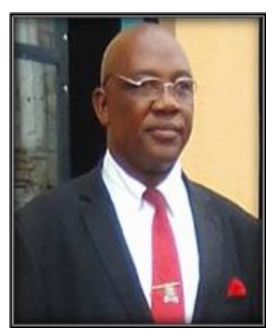

Zebulon Chukwudi Iwuala hails from Ogwa in Mbaitoli Local Government Area of Imo State Nigeria. He is an Associate Professor of Language Education in the National Institute for Nigerian Languages (NINLAN) Aba in Abia State of Nigeria. He obtained his Ma.Ed and Ph.D in Language Education at the University of Nigeria Nsukka. He has written many national and international journals.

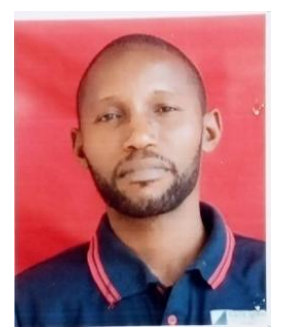

Imu Famous Oghoghophia was born in Arhagba-Okpe, on the $27^{\text {th }}$ may, 1985. He obtained his B.A, Linguistics (syntax) in the year 2010, from the Delta State University Abraka, Delta State Nigeria. He also earned his M.A Linguistics (syntax) and Ph.D Linguistics (Syntax and Semantics), from the University of Nigeria Nsukka, Nigeria, in the year 2015 and 2019 respectively.

He is a Lecturer in the National Institute for Nigerian Languages (NINLAN), Aba, Abia State. He is the Acting Head of Department, in the Department of Linguistics and Nigerian Languages Aba, Abia State. He currently teaches Syntax, Semantics and Sound System of the Urhobo Language in the National Institute for Nigerian Languages (NINLAN), Aba Abia State Nigeria. He is the Author of the following Articles: Imu, F. O. (2019).Verb of harvesting in Urhobo. In C. Okeke (Ed.), Semantics and study of language. Linguistics and Culture: Ugo gbuzou, A festschrift in Honour of Professor G. I. Nwaozuzu. University Press. And Imu, F. O. (2020). Argument structure of verb compounding in Urhobo. Journal of Nigerian Languages in a Globalised World: Description and Present Status. NILAS Vol. 4, no. 2

Dr. Imu is a member of LAN (linguistics association of Nigeria and Nigeria Language Project. 